University of Windsor

Scholarship at UWindsor

1984

\title{
On Nicholas of Autrecourt and the Law of Non-Contradiction
}

Leo Groarke

University of Windsor

Follow this and additional works at: https://scholar.uwindsor.ca/philosophypub

Part of the History of Philosophy Commons

\section{Recommended Citation}

Groarke, Leo. (1984). On Nicholas of Autrecourt and the Law of Non-Contradiction. Dialogue: Canadian Philosophical Review, 23 (1), 129-134.

https://scholar.uwindsor.ca/philosophypub/27

This Article is brought to you for free and open access by the Department of Philosophy at Scholarship at UWindsor. It has been accepted for inclusion in Philosophy Publications by an authorized administrator of Scholarship at UWindsor. For more information, please contact scholarship@uwindsor.ca. 

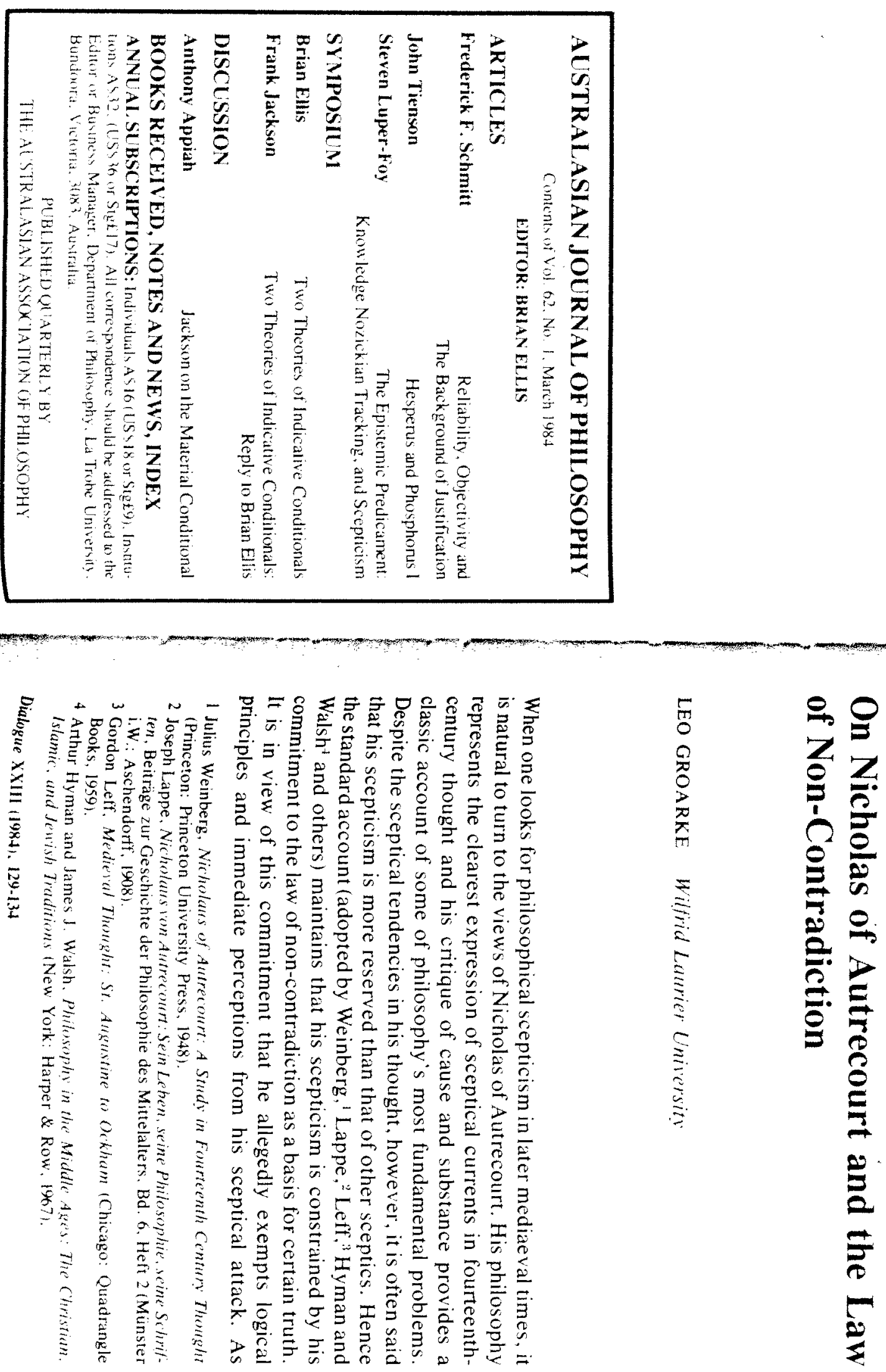


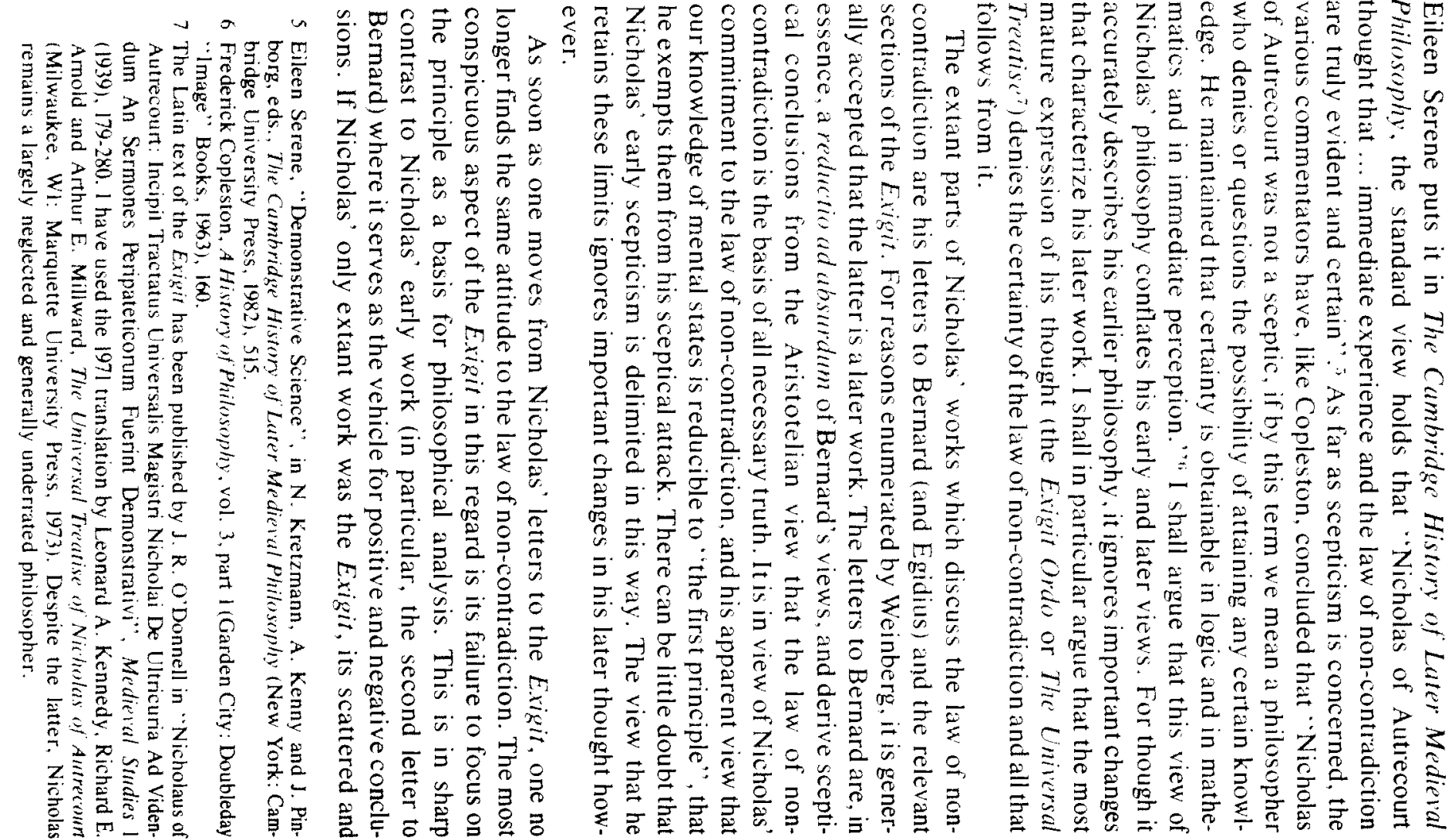

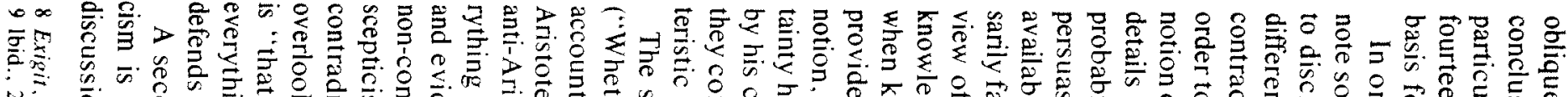

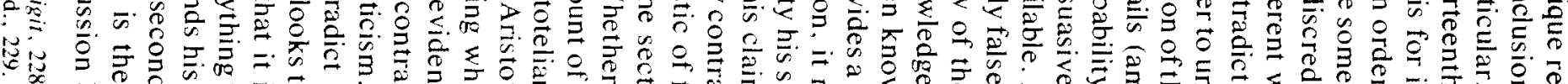

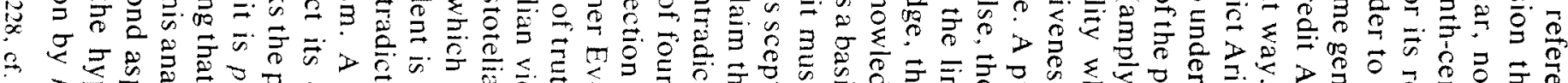
i

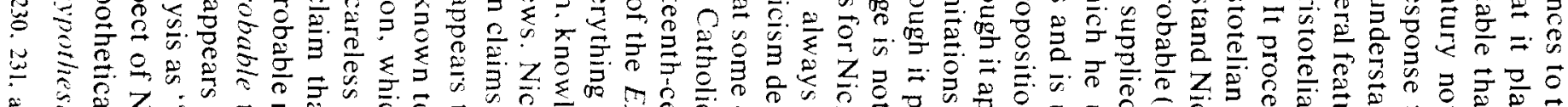

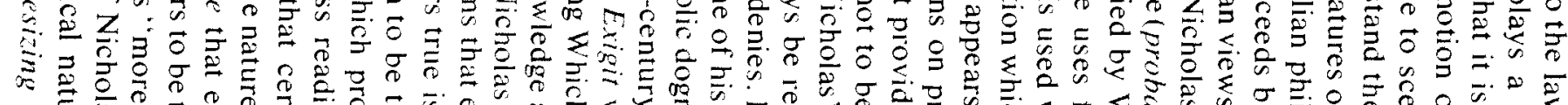

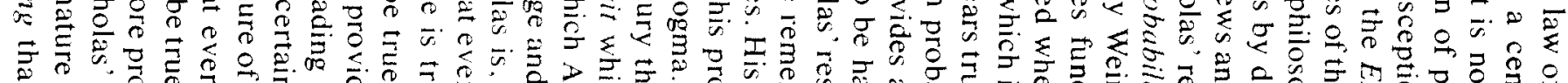

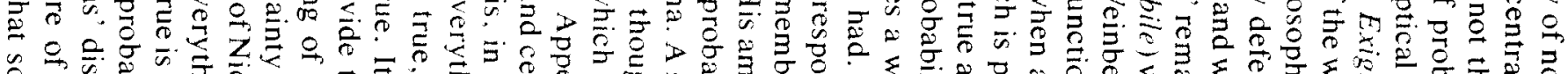

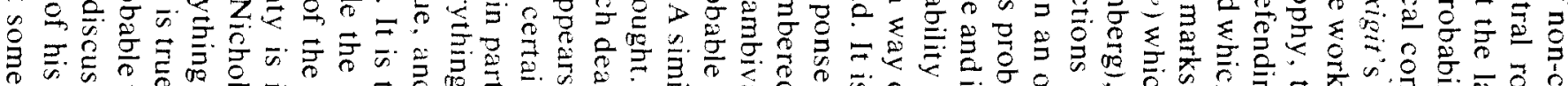

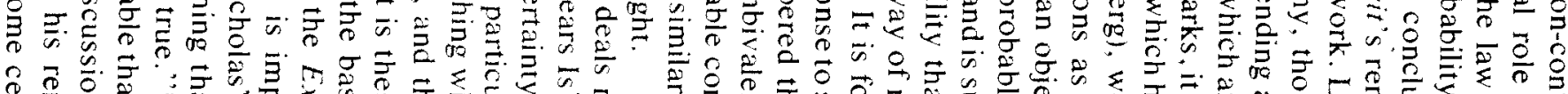

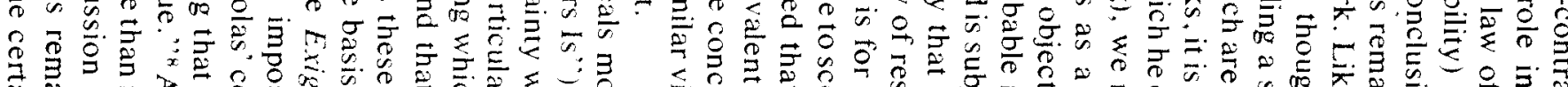

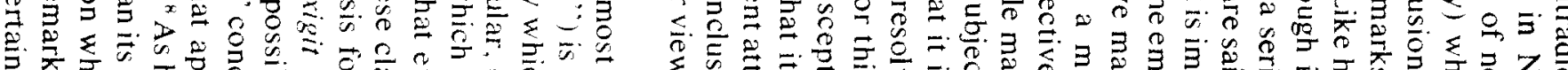

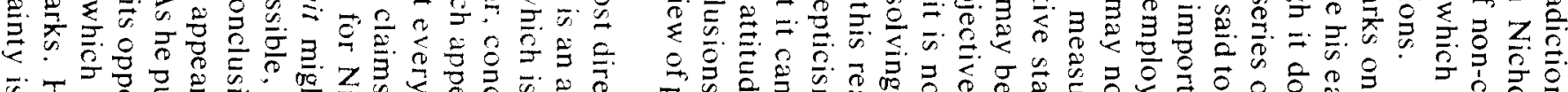

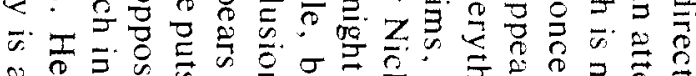

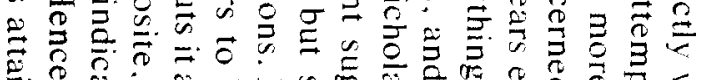
J.

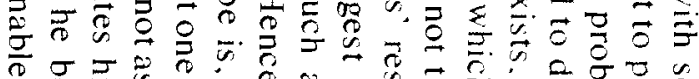

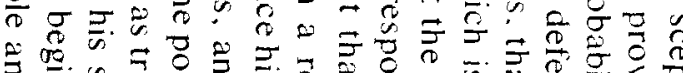

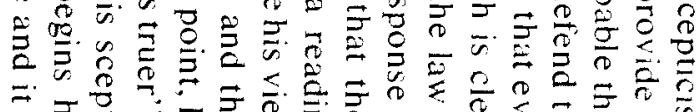

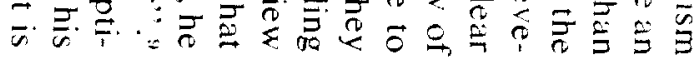

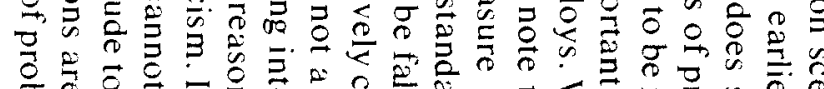

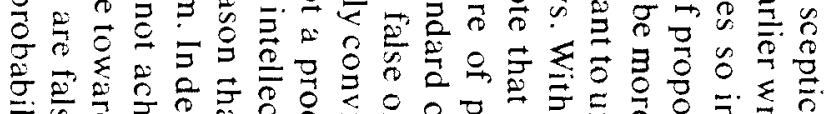

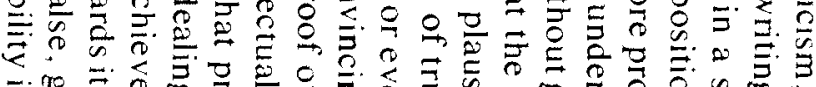

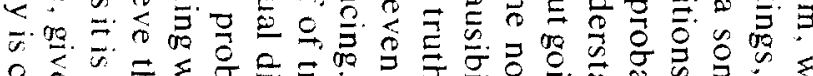

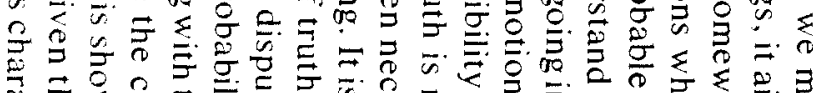

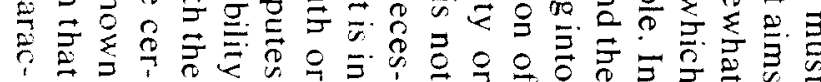

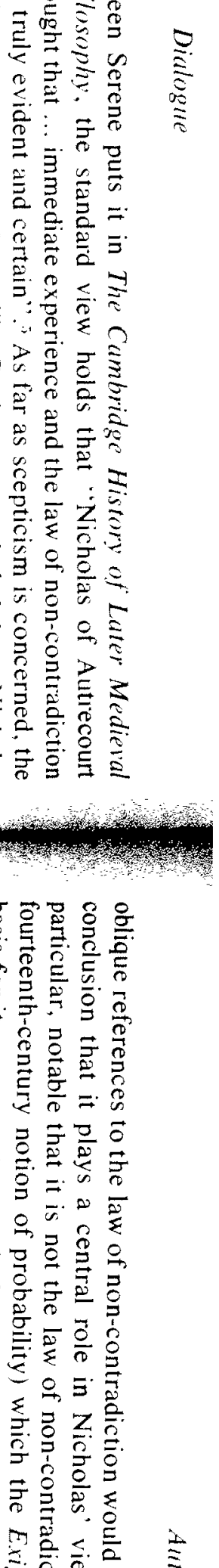
两 它 $\bar{\sigma} \Rightarrow \hat{\bar{\sigma}}$ 的 $\vec{\sigma} \bar{\sigma} \vec{\sigma}$ 


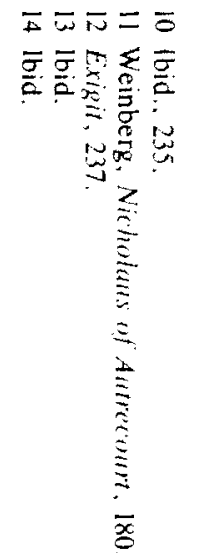

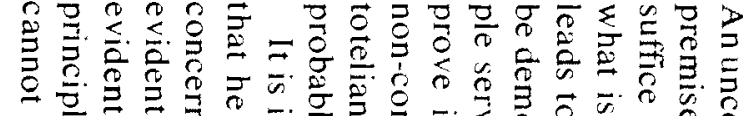

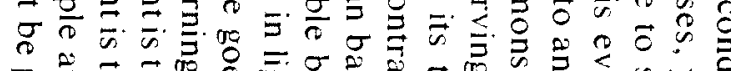

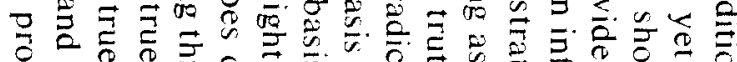

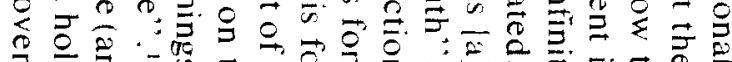

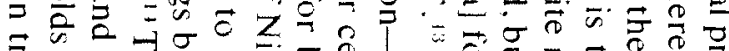

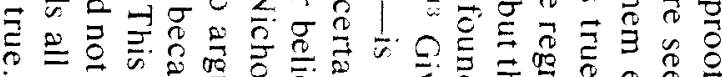

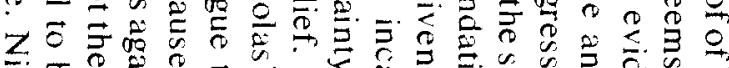

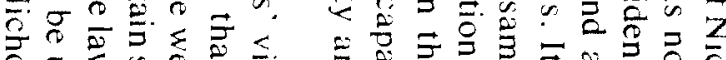

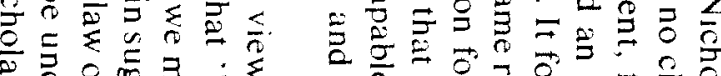

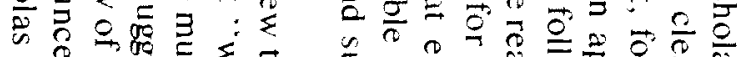

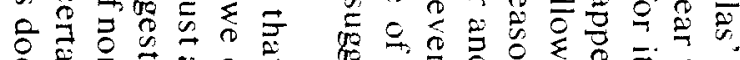

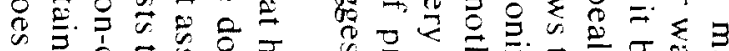

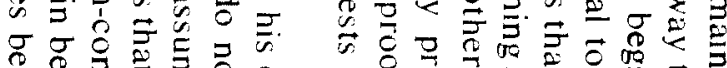

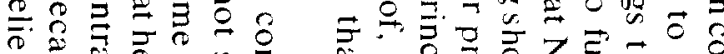

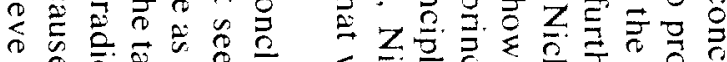

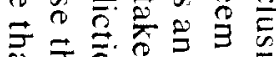
$\triangleq \overrightarrow{0} \varrho \stackrel{\infty}{\vec{\sigma}} \overrightarrow{0}$

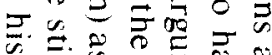

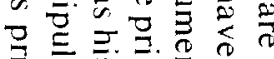

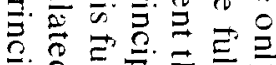
돓

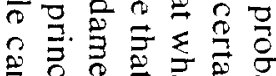

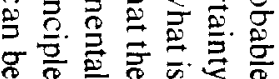

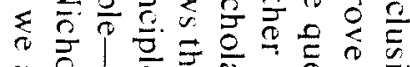

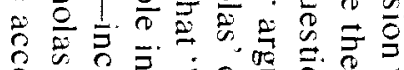

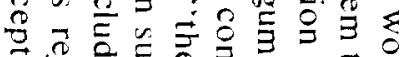

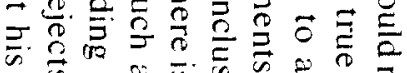

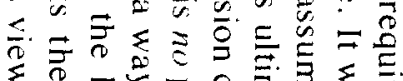

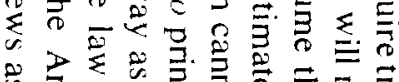

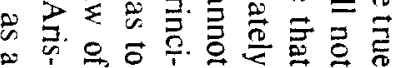

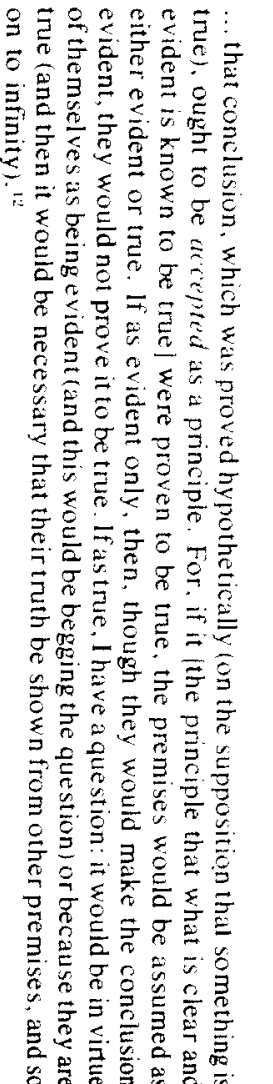

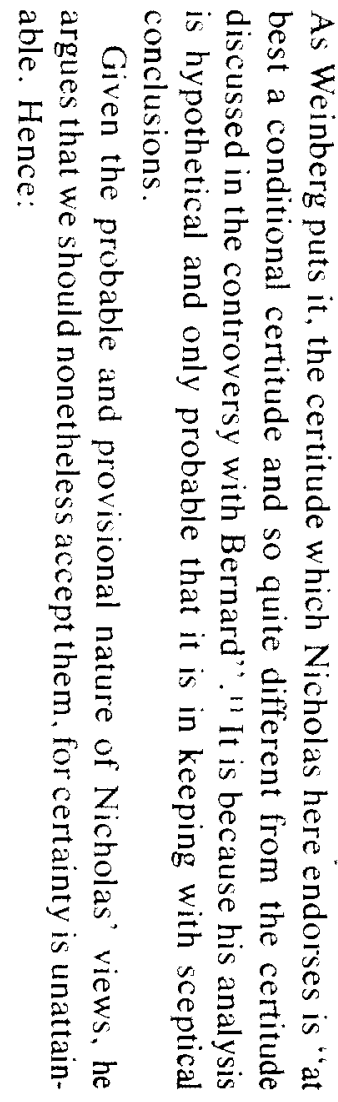

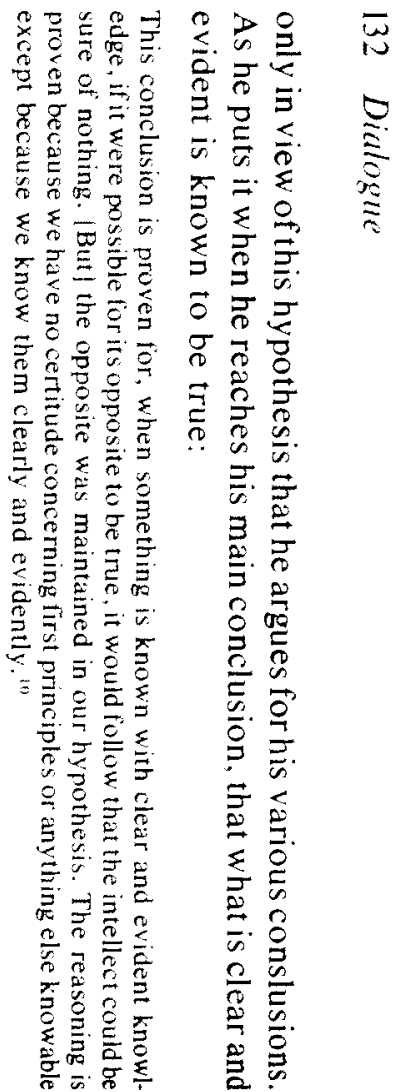

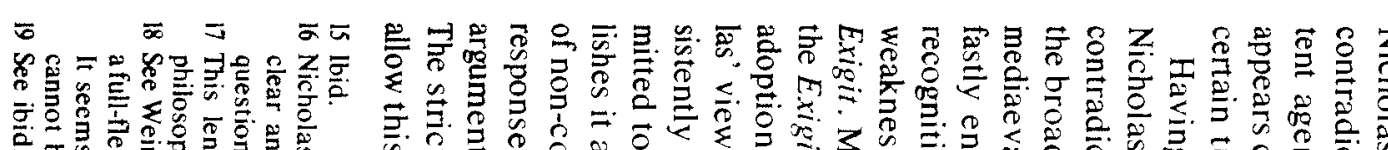

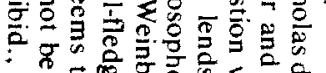

G日e

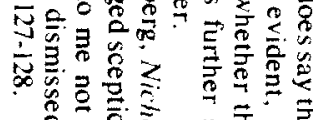

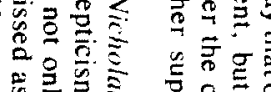

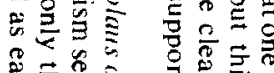

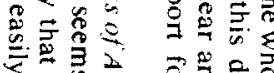

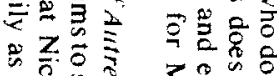

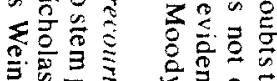

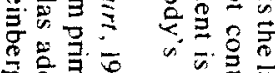

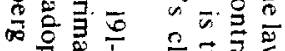

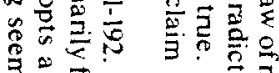

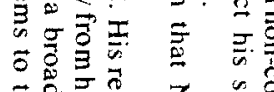

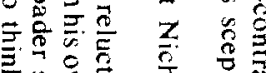

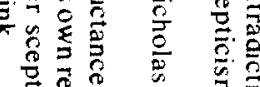

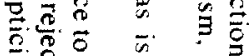

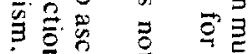

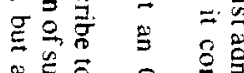

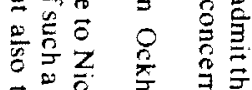

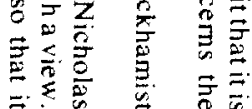

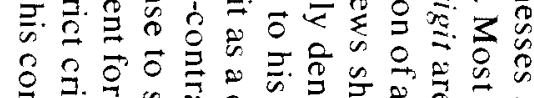

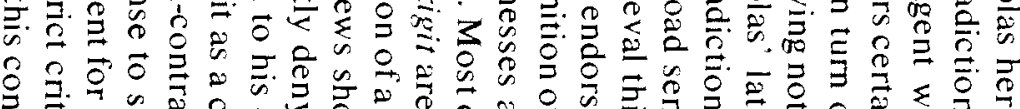

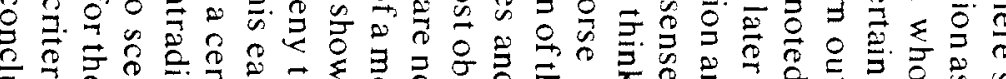

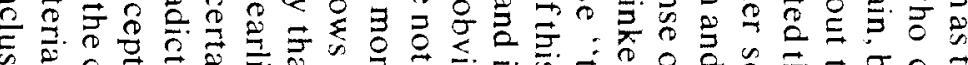

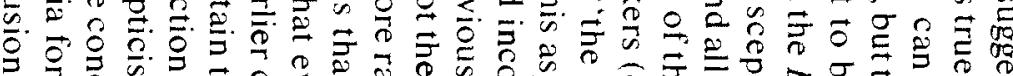

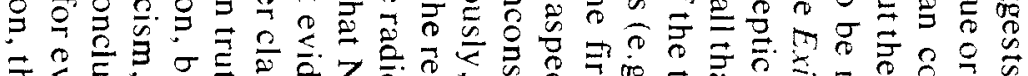

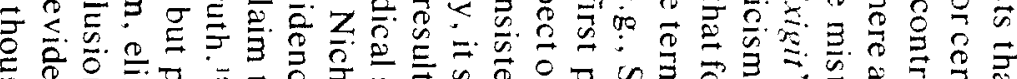

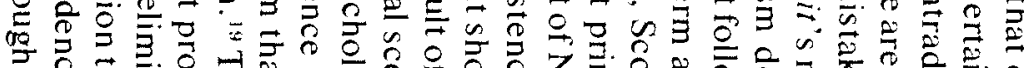

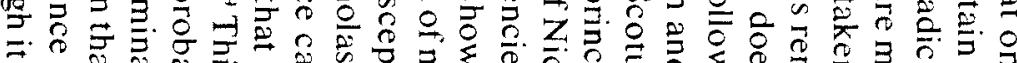

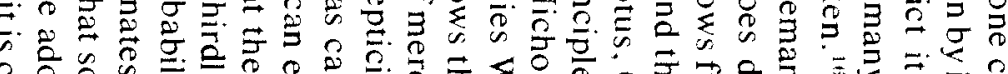

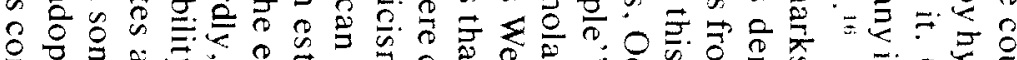

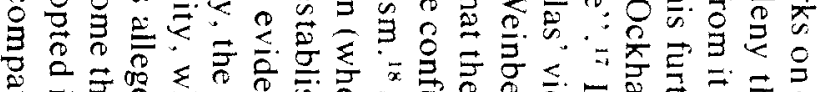

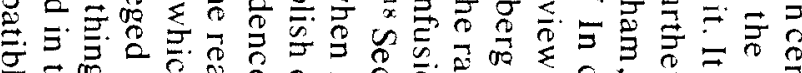

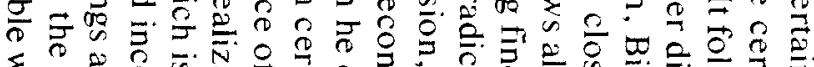

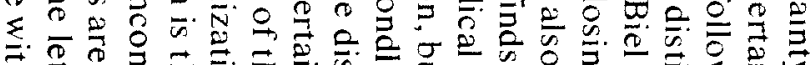

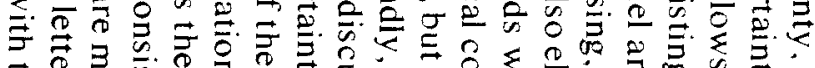

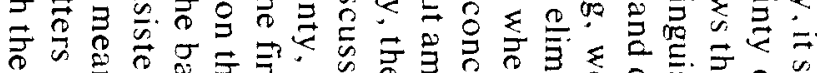

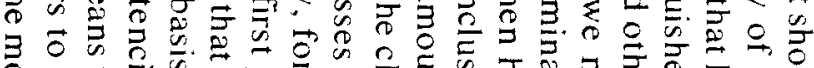

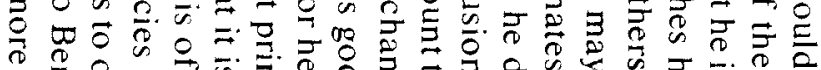

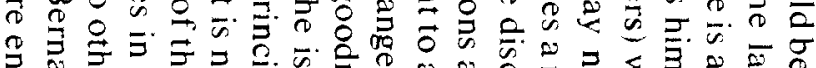

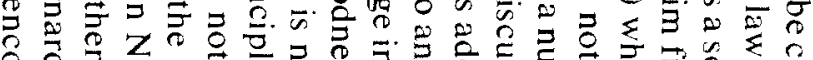

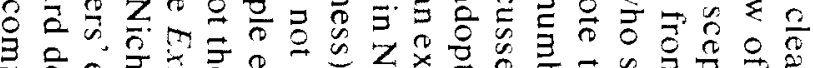

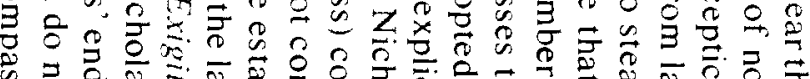

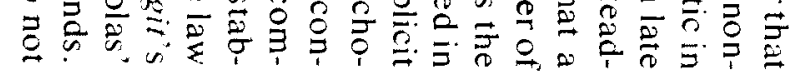

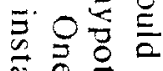

3 贾要

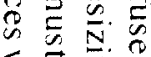

$\sum \vec{\square} \overrightarrow{0}$

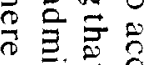

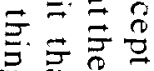

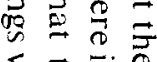

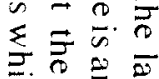

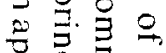

迅
무의

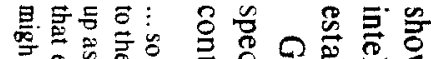
द्व

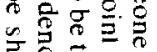

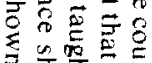
.

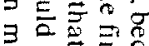

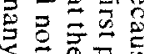

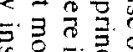

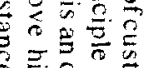

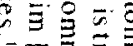

可

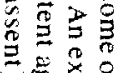

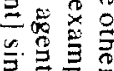

है항

Fे。

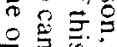

to

常.

$\Leftrightarrow \tilde{g}$

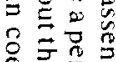

‥

4

$\exists$

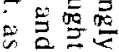

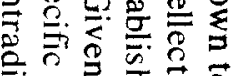

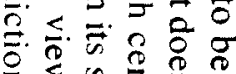
₹ $\sin _{0} \rightarrow$ $\Xi \leqslant \stackrel{8}{=}$

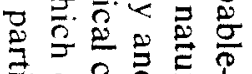

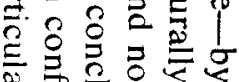

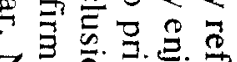

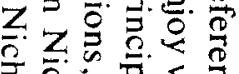

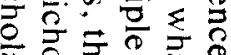

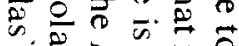

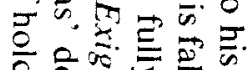
क 용 ज高骂 8 :

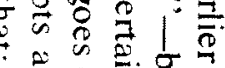

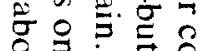

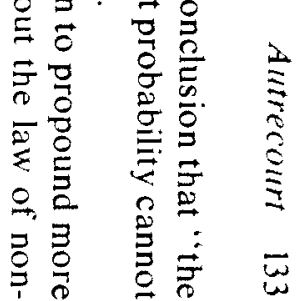



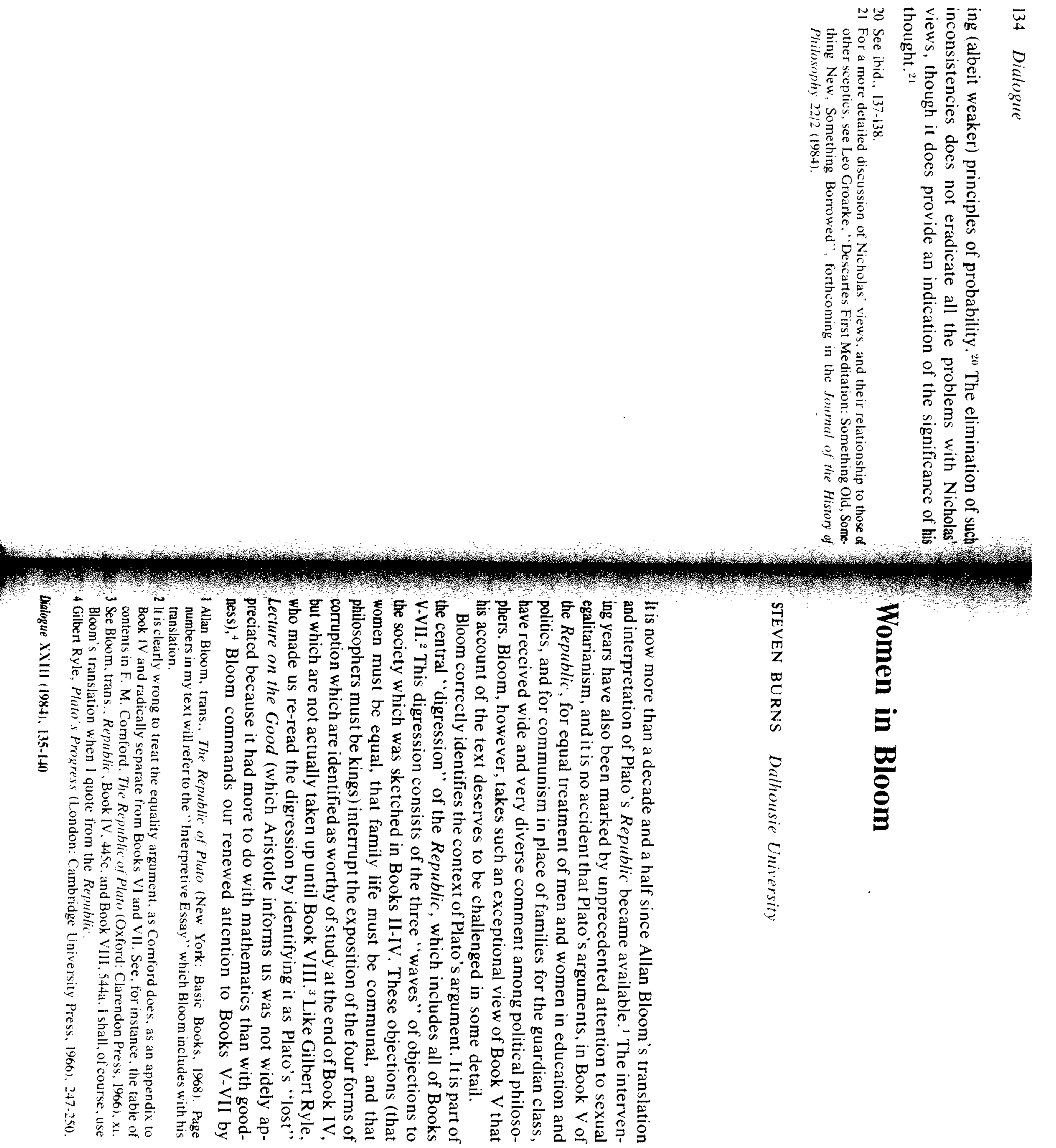